
\title{
Besearch S Surare \\ Using an OSCE Protocol in Evaluating Teaching Effectiveness of the CBL Teaching Method in Clinical Practice
}

\section{Shanshan Li}

Jiangsu Vocational College of Medicine

Junrong Wang

Suzhou Ruihua Hospital

Boyi Yang

Huazhong University of Science and Technology

Wei Jiang (D983859695@qq.com )

Jiangsu Vocational College of Medicine

\section{Research Article}

Keywords: OSCE, clinical practice, CBL teaching method

Posted Date: June 25th, 2021

DOl: https://doi.org/10.21203/rs.3.rs-611738/v1

License: (9) This work is licensed under a Creative Commons Attribution 4.0 International License. Read Full License 


\section{Abstract}

Background: With the continuing growth of learning resources, it is important to explore and analyze the effectiveness of a teaching method. Case-based learning (CBL) is defined in a number of ways depending on the discipline and type of 'case' employed. Objective Structured Clinical Examination (OSCE), a more objective and comprehensive assessment tool which could be used to evaluate clinical operation skills of clinical medical staff and students.

Objectives: To determine the effectiveness of CBL, in terms of students' feedback and formative OSCE grades.

Method: In the Chinese eight-year medical program practice stage, $\mathrm{CBL}$ teaching is carried out, and the results of OSCE are used to evaluate the effect of CBL teaching. The eight-year internship students were randomly divided into the traditional teaching group (TT group) $(n=26)$ and the CBL group $(n=24)$.

Result: The scores of the CBL group in the ability to collect medical history, operation of basic skills, test bank answers were all statistically better than those of TT group $(p<0.05)$. The physical examination ability score in CBL group was higher than the TT group but was not statistical different $(p>0.05)$.

Conclusion: The results showed that the performance of the $C B L$ teaching group was better than that of the TT group. The OSCE assessment is objective and comprehensive, but lacks analysis of abilities such as literature review, English skills and problems encountered in $\mathrm{CBL}$ teaching, which still needs further study to better promote CBL teaching.

\section{Introduction}

Case-Based Learning (CBL) focuses on the improving medical students' clinical thinking ability. A CBL definition is "The goal of the $\mathrm{CBL}$ is to prepare students for clinical practice, through the use of authentic clinical cases. It links theory to practice, through the application of knowledge to the cases, using inquirybased learning methods" [1]. By allowing students to actively participate in simulated case scenarios and learn in the form of discussion, CBL is often used to supplement traditional teaching methods. In recent years, medical schools nationwide have achieved beneficial outcomes using CBL teaching $[2,3]$. However, we need to be soberly aware that while CBL teaching can improve teaching outcomes, it may also yield unintended consequences associated with imbalance between the subject (students) and the guidance (teachers) or the students who cannot invest without interest [4]. Therefore, a more objective and accurate assessment of the CBL teaching reform is needed.

The Observed Structured Clinical Examination (OSCE), first described by Harden and colleagues in 1975 [5], is a new way to evaluate clinical operation skills of medical staff and medical students. OSCE is theoretically intended as an educational measure during medical training, allowing the assessment of students' abilities in a changing medical environment [6]. Some research stated that the scores obtained 
by medical students in OSCE have a strong predictive value for students' ability to identify and integrate relevant information and manage patients. [7]

In this research, we combine the OSCE and CBL teaching methods to evaluate the teaching effect of the new teaching model and provide a reference for the optimization of CBL teaching in the future.

\section{Objects And Methods}

\section{Objects}

A total of 50 students who entered the internal medicine internship in the eight-year medical program were randomly divided into either a traditional teaching group (TT group, 26 students) or a CBL group (24 students).

\section{Methods}

1. CBL teaching plan development

\section{Case selection}

The teaching plan was developed according to the eight-year textbook of "Internal Medicine", the actual situation of each ward of the internal medicine department of Tongji hospital affiliated to Huazhong University of Science and Technology and combined with the relevant regulations of the syllabus.

\section{CBL teaching}

[ (Students) select cases and collect medical history according to the internship situation;

$\square$ (Students) combine the cases, review the literature, and prepare.

Q (Students) report and ask questions and set learning goals under the guidance of the teachers.

प(Students) collect data, seek the answer.

$\square$ (Students) share results, and (teachers) summarize and evaluate.

प Results are integrated into clinical practice.

\section{OSCE evaluation}

OSCE standardized tests were conducted within two weeks after the completion of the clinical practice, including [6]: 
प Ability to collect medical history for assessment: as the examiner, standard patients (SP) assess the contents and skills of students' consultation. SP is the key link of this site assessment. Previous studies have shown that the teachers in charge of training and SP scored independently and their consistency reached $85 \%$, demonstrating the validity of assessment of SP.

[ Assessment of physical examination ability: according to the characteristics of the case of inquiry, key physical examination of SP shall be carried out within the specified time.

प Basic Skills Operation: according to the requirements of the internal medicine teaching syllabus, the corresponding skill operation is selected, with the emphasis on aseptic operation and humanistic care in the whole process.

( Experts were organized to compile the question bank according to the teaching syllabus. The question bank was in the form of multiple choices questions, which involved the diagnosis, differential diagnosis and the next treatment plan of related cases.

प The above results were combined to calculate the total score and evaluate the teaching effect of CBL.

\section{Statistical analysis}

SPSS19.0 software system was used for statistical analysis. Measurement data are expressed $\overline{\mathrm{x}}$ as $\pm \mathrm{S}$, and the $t$ test was used for comparison between groups, non-normal distribution indexes were tested by non-parametric test. $p<0.05$ set as statistically significant.

\section{Results}

\section{Comparison of two groups of general information}

There were no statistically significant differences between the CBL and TT group in gender, age, satisfaction with OSCE assessment method, satisfaction with teachers and professional title level of teachers $(p>0.05)($ Table 1$)$. 
Table 1

Comparison of general data between two group of students

\begin{tabular}{|llll|}
\hline & TT group( $\mathbf{n}=26)$ & CBL group( $\mathbf{n}=24)$ & $\mathbf{p}$ \\
\hline gender(male/female) & $10 / 16(38.5 \%)$ & $13 / 11(54.2 \%)$ & 0.275 \\
\hline age(year) & $24.00 \pm 0.63$ & $24.25 \pm 1.07$ & 0.327 \\
\hline Satisfaction with OSCE (Yes/No) & $23 / 3(88.5 \%)$ & $22 / 2(91.7 \%)$ & 0.713 \\
\hline Satisfaction with teacher(Yes/No) & $25 / 1(96.2 \%)$ & $24 / 24(100 \%)$ & 0.327 \\
\hline Teacher title & $26 / 0(100 \%)$ & $24 / 0(100 \%)$ & $\mathrm{N} / \mathrm{A}$ \\
(attending and above) & & & \\
\hline
\end{tabular}

Feedback analysis of teaching mode

Students in the CBL group $(n=24)$ believed that CBL teaching was more intuitive, helpful to grasp know e and improve practical ability (95.8\%), mobilize enthusiasm and cultivate divergent thinking (95.8\%), improve logical expression and interpersonal communication (91.2\%), and deepen the understanding of medical diseases (100\%) (Table 2).

Table 2

Feedback analysis of CBL teaching in CBL group

\begin{tabular}{|llll|}
\hline Advantages of CBL & \multicolumn{2}{c}{ number } & \multirow{2}{*}{ satisfaction } \\
\cline { 2 - 3 } & \multicolumn{2}{c}{ Yes } & No \\
\hline Intuitive, helpful to master knowledge, improve practical ability & 23 & 1 & $95.8 \%$ \\
\hline Arouse enthusiasm, cultivate divergent thinking & 23 & 1 & $95.8 \%$ \\
\hline Improve logical expression and interpersonal communication & 22 & 2 & $91.7 \%$ \\
\hline Deepen the understanding of medical diseases & 24 & 0 & $100 \%$ \\
\hline
\end{tabular}

Both groups of students agreed on the content design of the OSCE assessment method (TT group 100\% v.s. CBL group 95.8\%), the necessity of pre-test training (TT group $100 \%$ v.s. CBL group $95.8 \%$ ), the objective reflection of clinical ability (TT group $96.2 \%$ v.s. CBL group $91.2 \%$ ), and the objective and fair scoring of SP (TT group $96.2 \%$ v.s. CBL group 100\%), and there was no statistical difference between the two groups $(p>0.05)$ (Table 3$)$. 
Table 3

Feedback analysis of OSCE teaching

\begin{tabular}{|c|c|c|c|c|c|}
\hline & \multicolumn{2}{|c|}{ TT group $(n=26)$} & \multicolumn{2}{|c|}{ CBL group $(n=24)$} & \multirow[t]{2}{*}{$\mathbf{p}$} \\
\hline & Yes/No & satisfaction & Yes/No & satisfaction & \\
\hline Content design & $26 / 0$ & $100 \%$ & $23 / 1$ & $95.8 \%$ & 0.328 \\
\hline necessity of pre-test training & $26 / 0$ & $100 \%$ & $23 / 1$ & $95.8 \%$ & 0.328 \\
\hline Objective grading & $25 / 1$ & $96.2 \%$ & $22 / 2$ & $91.2 \%$ & 0.514 \\
\hline objectively reflect the clinical ability & $25 / 1$ & $96.2 \%$ & $24 / 0$ & $100 \%$ & 0.342 \\
\hline
\end{tabular}

As shown in Table 4, the scores of the CBL group in the ability to collect medical history (TT group 88.27 \pm 3.41 v.s. CBL group $91.79 \pm 3.95$ ), operation of basic skills (TT group $90.85 \pm 4.59$ v.s. CBL group 93.83 \pm 5.03 ), test bank answers (TT group $87.58 \pm 4.24$ v.s. CBL group $91.71 \pm 4.71$ ) and total scores of OSCE (TT group $89.01 \pm 2.99$ v.s. CBL group $92.19 \pm 3.29$ ) were all statistically significantly better than those of TT group $(p<0.05)$.

However, although the physical examination ability score was better than TT group (TT group $89.35 \pm$ 5.04 v.s. $C B L$ group $91.42 \pm 4.56)$, there was no statistical difference $(p>0.05)$.

Table 4

Comparison of Teaching Effects between TT group and CBL group

\begin{tabular}{|llll|}
\hline & TT group $(\mathbf{n}=26)$ & CBL group $(\mathbf{n}=24)$ & p \\
\hline collecting medical history ability & $88.27 \pm 3.41$ & $91.79 \pm 3.95$ & 0.001 \\
\hline Physical examination ability & $89.35 \pm 5.04$ & $91.42 \pm 4.56$ & 0.135 \\
\hline Basic Skills Operation ability & $90.85 \pm 4.95$ & $93.83 \pm 5.03$ & 0.040 \\
\hline Answer ability of the test bank & $87.58 \pm 4.24$ & $91.71 \pm 4.71$ & 0.002 \\
\hline OSCE score & $89.01 \pm 2.99$ & $92.19 \pm 3.29$ & 0.001 \\
\hline
\end{tabular}

\section{Discussion}

\section{The teaching effect of CBL in internal medicine is remarkable}

Applying the CBL teaching method resulted in improvements in many aspects of teaching effectiveness [8]. The students' subjective initiative has been given full play, their active learning ability has been enhanced, students have learned to ask questions actively, develop the ability to find answers by 
themselves, and cultivate the ability to obtain literature information through various ways [9]. Through interactive learning, discussion and communication between students and teachers, the theory learned is combined with clinical practice, and the clinical thinking ability and clinical skills are initially formed [10]. $\mathrm{CBL}$ also cultivates the students' communication skills and the sense of cooperation with others. Compared with the common cramming method, the CBL teaching method greatly improves teaching effectiveness: the classroom atmosphere is active, stimulating students' ability to think seriously and enhancing their participation and enthusiasm; stimulate students' interest in learning and help them master theoretical knowledge in an all-round way; improve logical thinking ability, enhance the ability of comprehensive analysis and problem solving; improve the ability of independent learning, exercise the ability of independent literature review, access to information, improve information literacy; broaden the students' scope of knowledge, contribute to the application of knowledge, and make the basic knowledge and clinical skills closely combined; improve students' ability of expression and make teachers better understand students' real inner thoughts and actual needs; enhance the spirit of teamwork, so that students learn to communicate with others, including classmates, teachers, patients effectively [11-13]. In this study, the basic information of the two groups of students is similar, and there is no statistical difference in various indicators (including gender, age, etc.). The students who participated in CBL teaching all expressed their affirmation of the CBL teaching method from different angles, and OSCE results further objectively verified the advantages of $\mathrm{CBL}$ teaching method.

\section{OSCE is more objective in assessing students' clinical competence}

OSCE is a new way to evaluate the clinical skills of clinicians, nurses, interns and medical students. It has been widely used in many countries and regions in the world since it was initiated by Dr. Harden in the United States in 1975. Many medical schools in the United States have been implementing OSCE to evaluate the clinical skills of medical students [13]. OSCE has many advantages, such as detecting clinical skills that cannot be detected by traditional written test and overcoming subjective differences of grading teachers. Therefore, the application of OSCE, especially the use of SP-OSCE research and practice in Europe and the United States has been surging, and at the same time, has also been promoted to the training of resident doctors and specialist examinations $[14,15]$. In recent years, the majority of studies have shown that the OSCE has many advantages in assessing the competence of practitioners, the clinical skills of medical students, and the expertise of specialists [16]. In addition, OSCE, as a method of objective assessment of students' abilities has great flexibility and can be operated according to the characteristics of different disciplines and objective conditions under the basic framework [17]. The evaluation of students' comprehensive ability has always been the focus of medical educators at home and abroad. Therefore, we introduced the method of OSCE into the eight-year internship examination. Through comparison and research, we used the main characteristics of its strong objectivity and multistation examination method for reference, and combined with the existing clinical comprehensive skills examination method, and established a comprehensive multi-station clinical examination method matching the objective conditions. 


\section{CBL and OSCE are mutually reinforcing}

In this study, in the OSCE assessment, we found that the scores of CBL group were better than those of TT group in terms of the ability to collect medical history, the scores of basic skill operation, the scores of question bank answers and the total scores of OSCE, with statistical differences. The usual CBL teaching process is actually the process of preparing cases for OSCE. Through CBL teaching, students can be familiar with the process and assessment content of OSCE, and their real clinical ability can be reflected in the actual OSCE assessment. Therefore, CBL teaching method and OSCE complement and promote each other.

\section{Conclusion}

In this study, we used OSCE to evaluate the difference in teaching outcomes between CBL teaching and traditional teaching. The use of the two mixed modes(OSCE combines $\mathrm{CBL}$ ) can significantly improve students' enthusiasm in class, cultivate divergent thinking, improve students' comprehensive ability to analyze problems and solve problems, and the evaluation results are more objective and reliable, which is worthy of promotion of the teaching mode. However, we found that OSCE's analysis of CBL teaching effect lacks analysis of students' other abilities (such as literature review, English ability, etc.) in CBL teaching. Further multi-center and large-sample studies are needed to improve our teaching method.

\section{Abbreviations}

CBL: Case-based learning; OSCE: Objectives Structured Clinical Examination; TT group: Traditional teaching group.

\section{Declarations}

\section{Ethical approval and consent to participate}

Ethics approval was obtained from Ethics Committee of Tongji Hospital Affiliated to Tongji Medical College of Huazhong University of Science and Technology.

\section{Consent for publication}

Not applicable.

\section{Availability of data and material}

The datasets used and/or analysed during the current study are available from the corresponding author on reasonable request.

\section{Competing interests}


Authors declare no competing interest.

\section{Funding}

The work was supported by the School-based topic of Jiangsu Vocational College of Medicine (grant no.: Q202107).

\section{Author contributions}

SL, JW, BY and WJ were involved in this study for designing and drafting the research protocol and the manuscript. SL, BY and WJ provided the search strategies. JW was responsible for coordinating the study. SL wrote the first draft of the manuscript. JW reviewed and commented the first draft of the paper. BY and WJ reviewed and edited the manuscript. All authors contributed to and approved the final manuscript.

\section{Acknowledgments}

The authors wish to thank $\mathrm{Na} \mathrm{Li}$ and lan Campbell for revising the English text.

\section{References}

1. Thistlethwaite JE, Davies D, Ekeocha S, Kidd JM, MacDougall C, Matthews P, Purkis J, Clay D. The effectiveness of case-based learning in health professional education. A BEME systematic review: BEME Guide No. 23. Med Teach. 2012;34(6): e421-444.

2. Ginzburg SB, Schwartz J, Gerber R, Deutsch S, Elkowitz DE, Ventura-Dipersia C, Lim YS, Lucito R. Assessment of medical students' leadership traits in a problem/case-based learning program. Med Educ Online. 2018;23(1):1542923.

3. Jhala $M$, Mathur $J$. The association between deep learning approach and case based learning. BMC Med Educ. 2019;19(1):106.

4. Bi M, Zhao Z, Yang J, Wang Y. Comparison of case-based learning and traditional method in teaching postgraduate students of medical oncology. Med Teach. 2019;41(10):1124-1128.

5. Harden RM, Stevenson M, Downie WW, Wilson GM. Assessment of clinical competence using objective structured examination. Br Med J. 1975;1: 447-451.

6. Daniels VJ, Pugh D. Twelve tips for developing an OSCE that measures what you want. Med Teach. 2018;40(12):1208-1213.

7. Sobh AH, Austin Z, Izham M I M, Diab MI, Wilby KJ. Application of a systematic approach to evaluating psychometric properties of a cumulative exit-from-degree objective structured clinical examination (OSCE). Curr Pharm Teach Learn. 2017;9(6):1091-1098.

8. Gu P, Guo J. Digital case-based learning system in school. PLoS One. 2017;12(11):e0187641. 
9. Grandhi A, Hohensee N, Cho EE, Nelsen CL. Faculty-driven data-mining for case-based learning and assessment. J Dent Educ. 2020 Jun 11.

10. Demetri L, Donnelley CA, MacKechnie MC, Toogood P. Comparison of Case-Based Learning and Traditional Lectures in an Orthopedic Residency Anatomy Course. J Surg Educ. 2021;78(2):679-685.

11. Fisher M, Smeiles C, Jnah AJ, Ruiz ME, Difiore T, Sewell K. Congenital Central Hypoventilation Syndrome: A Case-Based Learning Opportunity for Neonatal Clinicians. Neonatal Netw. 2019;38(4):217-225.

12. Bird EC, Osheroff N, Pettepher CC, Cutrer WB, Carnahan RH. Using Small Case-Based Learning Groups as a Setting for Teaching Medical Students How to Provide and Receive Peer Feedback. Med Sci Educ. 2017;27(4):759-765.

13. Tayce JD, Saunders AB, Keefe L, Korich J. The Creation of a Collaborative, Case-Based Learning Experience in a Large-Enrollment Classroom. J Vet Med Educ. 2021;48(1):14-20.

14. Sartori DJ, Olsen S, Weinshel E, Zabar SR. Preparing trainees for telemedicine: a virtual OSCE pilot. Med Educ. 2019;53(5):517-518.

15. Valentine D, Kurzweil A, Zabar S, Lewis A. Objective Structured Clinical Exams (OSCE) are a feasible method of teaching how to discuss a nonepileptic seizure diagnosis. Epilepsy Behav. 2019;100(Pt A):106526.

16. Kumar A. Tips for the cardiovascular OSCE. BMJ. 2016;355:h4383.

17. Nie R, Zhu F, Meng X, Zhang H, Xie S, Wu L, Yang J, Sun W. Application of OSCE for Stage Assessment in Standardized Training for Oral Residents. J Dent Educ. 2018 Sep;82(9):1000-1006. 